\title{
Alzheimer's disease: amino acid levels and brain metabolic status
}

\section{Maria Concetta Gueli \& Gennaro Taibi}

\section{Neurological Sciences}

Official Journal of the Italian

Neurological Society

ISSN 1590-1874

Neurol Sci

DOI 10.1007/s10072-013-1289-9

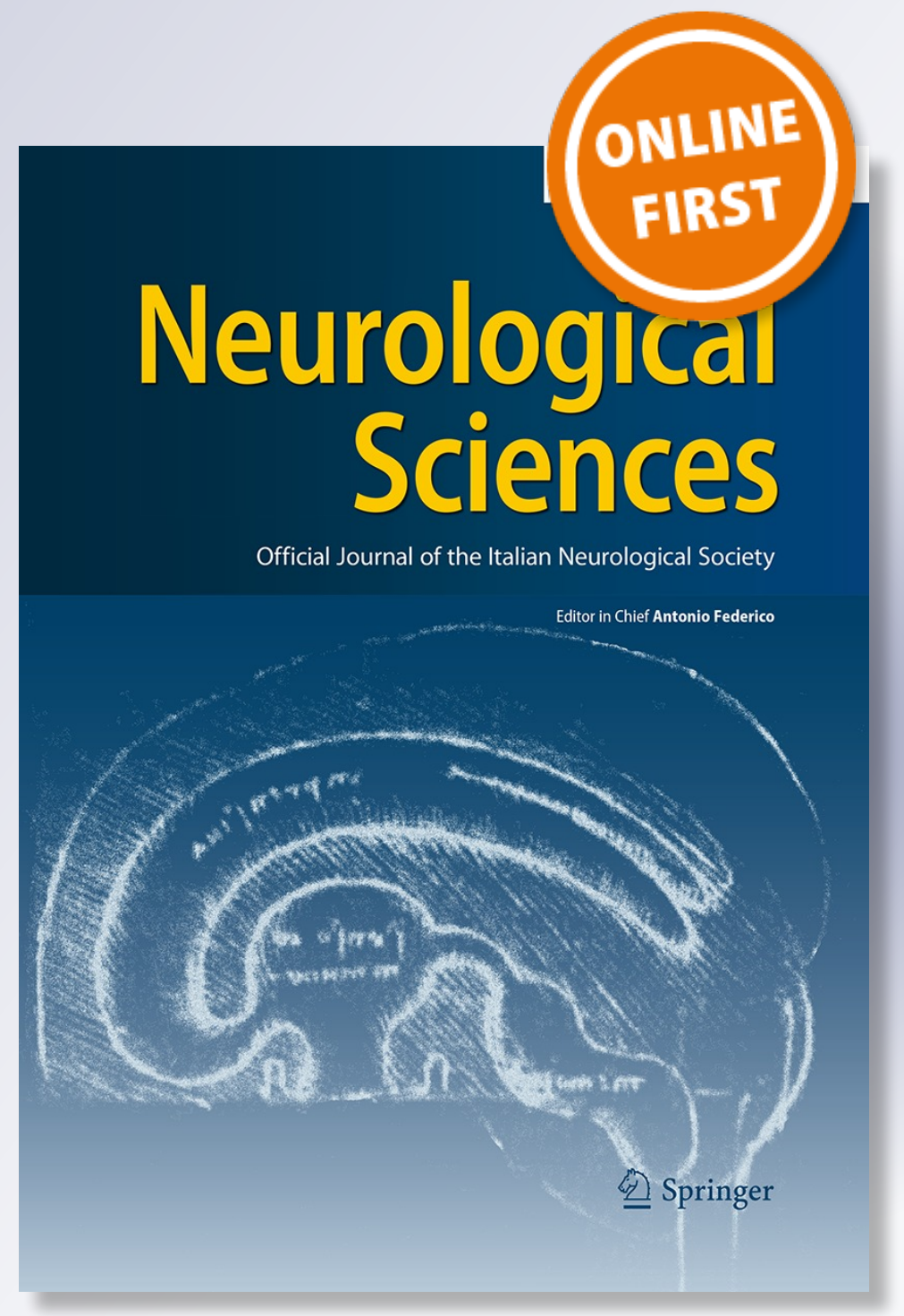

留 Springer 
Your article is protected by copyright and all rights are held exclusively by Springer-Verlag Italia. This e-offprint is for personal use only and shall not be self-archived in electronic repositories. If you wish to self-archive your work, please use the accepted author's version for posting to your own website or your institution's repository. You may further deposit the accepted author's version on a funder's repository at a funder's request, provided it is not made publicly available until 12 months after publication. 


\title{
Alzheimer's disease: amino acid levels and brain metabolic status
}

\author{
Maria Concetta Gueli · Gennaro Taibi
}

Received: 2 August 2012/ Accepted: 4 January 2013

(C) Springer-Verlag Italia 2013

\begin{abstract}
To study brain free amino acids and their relation with dementia we measured, by high-performance liquid chromatography (HPLC), the concentration of eight free amino acids, amines and related compounds. We used temporal cortex (TC) samples obtained from 13 Alzheimer's disease $(\mathrm{AD})$ patients and an equal number of agematched controls (AC). The patterns of free amino acids, amines and related compounds showed significant quantitative changes in $\mathrm{AD}$ conditions with respect to healthy ones. In Alzheimer patients, lower levels of GABA were found in the TC $(-57 \%)$. Amino acids glutamate (Glu), and aspartate (Asp) concentrations, also appeared significantly reduced in the TC of $\mathrm{AD}$ patients (Glu: $-30 \%$; Asp: $-40 \%$ ) when compared with controls. The significant gap between methionine (Met: $-30 \%$ ) and cystathionine (Cysta: $+60 \%$ ) levels in TC of $\mathrm{AD}$ people to controls, might suggest an under/over activity of the transmethylation and transsulphuration pathways, respectively. Glutamine (Gln) and Urea were an exception to this trend because their content was higher in $\mathrm{AD}$ patients than in controls. Albeit these compounds may have particular physiological roles, including the possible mediation of synaptic transmission, changes in amino acid levels and related compounds (detected in steady state) suggest a modified metabolic status in brains of $\mathrm{AD}$ patients that reveals a reduced function of synaptic transmission. Because several evidences show that patients might display quite different concentrations of neurotransmitters in brain
\end{abstract}

M. C. Gueli ( $\square) \cdot$ G. Taibi

Dipartimento di Biomedicina Sperimentale e Neuroscienze

Cliniche (BIONEC), Università di Palermo, Via del Vespro 129,

90127 Policlinico, PA, Italy

e-mail: mariac.gueli@unipa.it areas, assessing metabolites in different and well-characterized $\mathrm{AD}$ stages should be investigated further.

Keywords Alzheimer's disease · Brain · Temporal cortex · Amino acids $\cdot$ Neurotransmitters

\section{Introduction}

Alzheimer's disease (AD) is a neurodegenerative disorder characterized by a global impairment of higher cognitive functions mostly related to failure of synaptic connections long before neurons die [1]. Studies conducted on antemortem cerebral biopsy in neocortex of patients with $\mathrm{AD}$ show not only that neurotransmitter systems (cholinergic, noradrenergic, serotonergic and glutamergic neurons) and pyramidal neurons are prematurely damaged in the course of the disease [2], but also that the loss of cholinergic and pyramidal neurons is related to the severity of dementia evolution [3]. The molecular etiology of $\mathrm{AD}$ is still incomplete. Neuronal death can occur by either apoptotic or necrotic mechanisms [4]. All studies on humans with $\mathrm{AD}$ indicate the amyloid- $\beta$-peptide $(\mathrm{A} \beta \mathrm{P})$ accumulation in the cerebral cortex as an early and invariant event in the development of $\mathrm{AD}$ pathology, preceding other brain lesions and clinical symptoms by many years or decades [5]. Despite extensive research, today the primary events underlying the neuropathological changes are still like pieces of a puzzle that cannot be fitted together. Thus, in view of the importance of collecting more useful information on the biochemical features characterizing the neurodegeneration in $\mathrm{AD}$, we analyzed the variations in the patterns of free amino acids and related compounds in brain extracts in the disease with respect to AC. In the light of previous works on this matter [6], the described data are 
also employed to establish a correlation between such amino acids variation and the modification of their function.

\section{Materials and methods}

Brain specimens in AC and AD neuropathologically confirmed cases (see Table 1) have been used to determine the amino acid level patterns and related compounds. Brain tissue samples (temporal cortex, grey matter) were received from the MRC London Brain Bank for Neurodegenerative Diseases, Department of Neuropathology, Institute of Psychiatry, London, UK. The AD patients fulfilled the National Institute of Neurological and Communicative Disorders and Stroke and Alzheimer's Disease and Related Disorders Association (NINCDS/ADRDA) criteria for probable AD [7]. The histological diagnosis of $\mathrm{AD}$ was established and was consistent with the CERAD criteria [8] for a sure diagnosis of AD. Control subjects had not any history of dementia, nor other neurologic disease. Neuropathologic examination confirmed the absence of any significant gross or microscopic brain abnormalities in controls. Specimens were transported to Palermo laboratory on dry ice and the freezing chain was never interrupted. The brain samples were coded and kept frozen at $-70{ }^{\circ} \mathrm{C}$ until used.

Amino acid standards, protease inhibitors, derivatization reagents and other chemical reagents (A-grade or for chromatographic use) were purchased from Sigma (Milan, Italy).

$\mathrm{AC}$ and $\mathrm{AD}$ samples are weighed promptly with a microbalance (Mettler-H72, Zurich, Switzerland), thawed on ice, minced and then mechanically homogenized in an ice-cold solution of $10 \mathrm{mM}$ Hepes buffer, $\mathrm{pH} 7.4$ con-

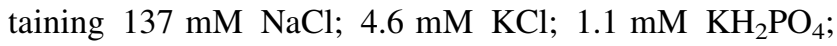
$0.6 \mathrm{mM} \mathrm{\textrm {MSO } _ { 4 }}$ using a Wheaton Dounce tissue grinder. To prevent artifactual proteolysis, the Protease Inhibitor Cocktail (Sigma) is added to the mixture along with $0.2 \mathrm{mM}$ dithiothreitol. Homogenate is then centrifuged at $12,000 \mathrm{~g}$ for $20 \mathrm{~min}$ at $4{ }^{\circ} \mathrm{C}$ with a Beckman L8-70M

Table 1 Characterization of study groups by number, age, post-mortem interval, male-to-female ratio

\begin{tabular}{lll}
\hline & Alzheimer patients & Age-matched patients \\
\hline$N$ & 13 & 13 \\
Age (year) & $71.1 \pm 7.6$ & $72.7 \pm 9.7$ \\
Sex (m/f) & $3 / 2$ & $5 / 2$ \\
PMI (h) & $30.09 \pm 0.67$ & $31.24 \pm 0.58$ \\
\hline
\end{tabular}

Data are reported as mean \pm SEMs

$P M I$ postmortem interval refrigerated centrifuge. Supernatants are removed, deproteinized with $100 \mu \mathrm{l}$ of sulfosalicylic acid (50\% solution), and again centrifuged at 7,500g for $5 \mathrm{~min}$ at $4{ }^{\circ} \mathrm{C}$ with an ALC 4239R refrigerated centrifuge. The clear supernatants are then withdrawn, filtered through Millipore Millex-HV $(0.45 \mu \mathrm{m})$ and used for the amino acids and related compounds determination.

The free amino acids and related compounds contents of brain specimens have been analyzed through a Beckman's System 6300 High-Performance Amino Acid Analyzer (Beckman Coulter S.P.A. Milan, Italia) with the procedure described by Borum [9] using an Li high-performance column $(10 \mathrm{~cm})$ with the buffers $\mathrm{Li} \mathrm{A} / \mathrm{Li} \mathrm{B}$ at a flow rate of $30 \mathrm{ml} / \mathrm{min}$ at $1,600 \mathrm{psi}$ at a column temperature of $34-63{ }^{\circ} \mathrm{C}$. It has been used ninhydrin as a colorimetric reagent. The analysis time is $53 \mathrm{~min}$. Data integration has been performed by a Shimadzu Chromatopac C-R3A. Clinical and autopsy data are given in Table 1. Statistical analysis has been performed using Primer of Biostatistics (Stanton A. Glantz, McGraw-Hill-Libri, New York) and Prism (GraphPad Software, San Diego, USA). Differences between controls and pathological patients have been tested by independent two-sample $t$ test with $P<0.05$ accepted as significant.

\section{Results}

As shown in the Table 2, a total of 10 different compounds between free amino acids, amine species and related compounds are determined in the TC brain of the AC and AD patients. In general, almost all amino acids and ammonia levels are significantly lower in AD when compared with AC patients ones. It was found that Met levels showed a decrease in about $30 \%$ in $\mathrm{AD}$ patients with respect of control values. When compared with $\mathrm{AC}$, GABA, Glu, Asp and ornithine (Orn) levels are markedly and significantly decreased $(-33,-30,-40,-62 \%$, respectively) in $\mathrm{TC}$ of $\mathrm{AD}$ brain subjects. The change in Cysta, urea and Gln levels are an exception to this trend, their contents are greater in $\mathrm{AD}$ people $(+63,+124$, $+60 \%$, respectively) than in AC cortex.

Another interesting evidence from chromatographic analysis in pathological brain extracts is the lowered peaks of ammonia $(-25 \%)$. The arginine (Arg) content in AD group is slightly lower $(-27 \%)$ than in the AC.

\section{Discussion}

Interesting considerations emerge from the evaluation of amino acids, amine patterns and related compounds from soluble extracts in brain TC of patients affected by AD 
Table 2 Levels of L-amino acids and related compounds found in human temporal cortex extracts of Alzheimer patients and age-matched patients

\begin{tabular}{llll}
\hline Compound & $\begin{array}{l}\text { Alzheimer } \\
\text { patients } \\
(\mu \mathrm{mol} / \mathrm{g} w w t)\end{array}$ & $\begin{array}{l}\text { Age-matched } \\
\text { patients } \\
(\mu \mathrm{mol} / \mathrm{g} w w t)\end{array}$ & $\begin{array}{l}\text { Ratio } \\
\text { Alzheimer/ } \\
\text { control }\end{array}$ \\
\hline Urea & $13.8 \pm 11.72^{\mathrm{a}}$ & $6.16 \pm 5.9$ & 2.240 \\
Aspartate (Asp) & $1.80 \pm 1.12^{\mathrm{a}}$ & $3.00 \pm 1.26$ & 0.600 \\
Glutamate (Glu) & $4.90 \pm 1.69^{\mathrm{a}}$ & $7.02 \pm 1.65$ & 0.698 \\
Glutamine (Gln) & $2.68 \pm 1.37^{\mathrm{a}}$ & $1.67 \pm 0.61$ & 1.600 \\
Methionine (Met) & $0.23 \pm 0.09^{\mathrm{a}}$ & $0.32 \pm 0.11$ & 0.718 \\
Cystathionine (Cysta) & $0.80 \pm 0.05^{\mathrm{a}}$ & $0.49 \pm 0.33$ & 1.632 \\
GABA & $0.60 \pm 0.16^{\mathrm{a}}$ & $0.90 \pm 0.28$ & 0.666 \\
Ammonia & $0.15 \pm 0.03^{\mathrm{a}}$ & $0.20 \pm 0.07$ & 0.750 \\
Ornithine (Orn) & $0.03 \pm 0.01^{\mathrm{a}}$ & $0.08 \pm 0.07$ & 0.370 \\
Arginine (Arg) & $0.29 \pm 0.14^{\mathrm{a}}$ & $0.40 \pm 0.11$ & 0.725 \\
\hline
\end{tabular}

Data are given as mean \pm standard deviation (SD) found in temporal cortex extracts from 13 Alzheimer patients and 13 normal subjects

Significance between groups was tested by two-sample independent $t$ test with $P<0.05$ accepted as significant

$w w t$ wet weight tissue

${ }^{a}$ Indicates values which are statistically significant between $\mathrm{Alz}$ heimer and control

when compared with AC. The data reveal some changes in almost all amino acids levels detected at steady state. The slightly decrease in Met levels in AD patients shows a related deficit of brain structural proteins [10]. As for amino acids, such as Asp, Glu and Met the damage consequent to their decrease will not only lead to a changed protein turnover in $\mathrm{AD}$ conditions, but also to a reduced availability of the special metabolites or neurotransmitters or precursors. When compared with the controls, Met levels are significantly reduced in $\mathrm{AD}$ group thus we think this drastic reduction could be the outcome of a metabolic pathway disorder, but it could also be a cause. Met, in the form of $S$-adenosylmethionine (SAM), is the principal donor of methyl groups in numerous methyltransferase reactions [11]. Met levels may be reduced through excessive utilization in polyamine biosynthesis. Previous studies have demonstrated markedly elevated SAM decarboxylase activity, ornithine decarboxylase (ODC) protein and spermidine levels so far [12]. As reported, SAM levels are severely decreased in AD patients' brain and CSF [13]. Moreover, MAT2A gene expression in human hepatocarcinoma cells was modulated by Met deprivation through its conversion into SAM [14]. Therefore, a Met decrease in AD patients' brain could also be an early signal or an adaptive response to the change of its modified status, and SAM level variation could be a key event for homeostasis of the brain too. The quite different pattern between Cysta levels in $\mathrm{AD}$ patients compared with $\mathrm{AC}$ caught our attention. In fact, a high concentration of Cysta in the TC of $\mathrm{AD}$ patients in our experimental conditions, was an unexpected finding. The sharp Cysta levels could suggest the existence in $\mathrm{AD}$ brains of a particular relationship between the amount of the enzymes involved in the synthesis by cystathionine $\beta$-synthase activity and in the cleavage of the amino acid by $\gamma$-cystathionase activity. As reported, the human brains analysed by autopsy on normal subjects contain a high concentration of Cysta [15]. The presence of large amounts of Cysta in affected human brain and in developing brain has been demonstrated [16]. Thus, the surplus of Cysta level in AD brain could be used to increase cysteine pool for glutathione synthesis, the major redox buffer in mammalian cells $[17,18]$.

A decrease in Arg content, for instance, may have the slowdown of the citrulline-NO cycle as a consequence [19]. Furthermore, Arg decreases may partly explain a reduced local synthesis of creatine together with the markedly impaired activity of creatine kinase (CK) BB isoform, detected in AD brains [20].

A marked decrease is observed in GABA neurotransmitter in AD brain. GABA deficit in senile dementia is associated with a decreased glutamate decarboxylase activity [21]. It may be determined by a more active catabolism from the glial GABA transaminase, but it may also reflect the reduced availability of Glu, as our experimental observations have shown. Gln is an exception to this trend, its content being 1.6-fold greater in AD than in AC cortex, but it only partially contributes to the Glu homeostasis by the aging of the glutaminase activity. In fact, graded reductions of glutaminase (GA) are combined with increases in glutamine synthetase (GS) activity [22, 23]. Our results suggest an in vivo adaptation of the glutamate-glutamine cycle to avoid neuronal death. The increase in Gln level is a really expected result if the observed activation of glia cells in neurodegeneration is taken into consideration [24]. Hence, the GS activity should be monitored as it seems behaving like a switch under pathological conditions in brain. The decreased content of Glu in AD TC suggests its possible withdrawal to increase Gln levels in astrocytic cells. This agrees with the previous data on decreased Glu and higher Gln content reported for the same cortex area in $\mathrm{AD}$ postmortem brain $[25,26]$. A lower Asp concentration, for instance, is detected in all $\mathrm{AD}$ temporal cortex specimens and we consider it may be the result of a reduced Glu concentration, as in brain the main route of Asp biosynthesis is that of glutamate-oxalacetate transamination.

Another interesting evidence from chromatographic analysis in pathological brain extracts is the lowered peaks of ammonia in AD brains. The lowered ammonia level, together with its involvement in Gln biosynthesis, might be the result of the remarkable increase in urea in brain 
pathological group. This increased level could be a consequence of the altered urea diffusion in affected brain areas, determined by permeability change of the blood-brain barrier that causes its retention or a higher influx. It rather appears more realistic to assume arginine broken down by overexpressed arginase hetero-form to give unpredictable urea levels in the brain. This may contribute to a dangerous arginine depletion that may be a prerequisite for translational control of iNOS mRNA and NO generation [27]. A marked decrease in ornithine (Orn) in $\mathrm{AD}$ could be the virtual warning bell of a significantly increased inducible ODC activity. A recent study has shown how an overexpression of ODC had caused cellular transformation, suggesting that the key enzyme for polyamine biosynthesis should be regarded as a proto-oncogene product [28]. Recent observations have showed an attempted re-entry into the cell division cycle of the neurons in AD [29] and since neuronal maturation is associated with effective escape from the cell division cycle, emergence of quiescence may be deleterious. The current data analysis of free amino acids in brain temporal cortex of AD individuals once more points out some common aspects of the neuronal damage. Furthermore, they solicit the question whether such a dramatic amino acids variation may be almost exclusively associated with an increased protein catabolism by calpain and other proteases [30,31], if it may also be due to a deficient protein biosynthesis or excess brain protein oxidation [10] (or to a long-term process imbalance).

The apparent deficit in amino acids and neurotransmitters in $\mathrm{AD}$ degenerating brains may be a protective device for a progressively reduced function, based on a long-term adaptation mechanism which might start early in life. Moreover, although not as widely appreciated, the regulation of cellular functions by major (carbohydrates, fatty acids, sterols) and minor (minerals, vitamins) dietary constituents (including the control of the gene expression), is well documented in prokaryotes and lower eukaryotes [32]. The idea amino acids can regulate gene expression in mammalian cells has been considered [33]. Mammalian cells can also adapt to dietary or pathological fluctuation in amino acids availability. It has been shown that a number of genes have specifically changed their expression levels following amino acids deprivation [34]. Under such limiting conditions, amino acids could be playing a signalling role in affected brains, conveying regulatory messages to the transcriptional machinery and affecting the turnover of specific mRNA and proteins. For instance, limitation of several amino acids greatly increases the expression of the gene encoding growth factors, binding proteins, enzymes, amino acids transport systems, retrograde tRNA transport $[35,36]$. Another possibility is that this deficit could be the result of an ineffective attempt by brain tissues in repairing or gathering energy. These observations, taken together, suggest that a condition of amino acid stress anyway caused can be crucial in starting changes in brain metabolic status. Moreover, such an adaptive process involves both neuron and glia populations, with an exaltation of glial function with respect to neuron function as a consequence of neuronal control loss [37]. To define if these present findings are trait or state markers of $\mathrm{AD}$ it needs further studies on brain samples obtained from AD patients with well-characterized stages of disease.

Acknowledgments We thank Prof Gert Lubec for critical reading of the manuscript.

\section{References}

1. Hyman BT (1996) Anatomy of pathological alterations in Alzheimer's disease. In: Wasco W, Tanzi RE (eds) Molecular mechanisms of dementia. Humana Press Inc., Totowa, pp 219-223

2. Nitsch RM (1996) From acetylcholine to amyloid: neurotransmitters and the pathology of Alzheimer's disease. Neurodegeneration 5:477-482

3. Bowen DM, Allen SJ, Benton JS, Goodhardt MJ, Haan EA, Palmer AM, Sims NR, Smith CCT, Spillane JA, Esiri MM, Neary D, Snowdon JS, Wilcok GK, Davison AN (1983) Biochemical assessment of serotonergic and cholinergic dysfunction and cerebral atrophy in Alzheimer's disease. J Neurochem 41:266-272

4. Yuan J, Yankner BA (2000) Apoptosis in the nervous system. Nature 407:802-809

5. Hardy JA, Higgins GA (1992) Alzheimer's disease: the amyloid cascade hypothesis. Science 25:184-185

6. Tarbit I, Perry EK, Perry RH, Blessed G, Tomlinson BE (1980) Hippocampal free amino acids in Alzheimer's disease. J Neurochem 35:1246-1249

7. Tierney MC, Fisher RH, Lewis AJ, Zorzitto ML, Snow WG, Reid DW, Nieuwstraten P (1988) The NINCDS-ADRDA work group criteria for the clinical diagnosis of probable Alzheimer's disease. Neurology 38:359-364

8. Mirra SS, Heyman A, McKill D, Sumi SM, Crain BS, Brownlee LM, Vogel SS, Hughes JP, Van Bele G, Berg L (1991) The consortium to establish a registry for Alzheimer disease (CERAD II). Standardisation of the neuropathological assessment of Alzheimer's disease. Neurology 41:479-486

9. Borum PR (1985) Manual for amino acid analysis of physiological samples. Atlanta GA American Association for Clinical Chemistry 37th National Meeting

10. Smith CD, Carney JM, Starke-Reed PE, Oliver CN, Stadtman ER, Floyd RA, Markesbery WR (1991) Excess brain protein oxidation and enzyme disfunction in normal aging and in Alzheimer disease. Proc Natl Acad Sci USA 88:10540-10543

11. Cantoni L (1975) Biological methylation: selected aspects. Annu Rev Biochem 44:435-451

12. Morrison LD, Bergeron C, Kish SJ (1993) Brain S-Adenosylmethionine decarboxylase activity is increased in Alzheimer's disease. Neurosci Lett 154:141-144

13. Bottiglieri T, Godfrey P, Flynn T, Carney MWP, Toone BK, Reynolds EH (1990) Cerebrospinal fluid S-adenosylmethionine in depression and dementia: effects of treatment with parenteral and oral S-adenosylmethionine. J Neurol Neurosurg Pschiatry 53: 1096-1098

14. Martínez-Chantar ML, Latasa MU, Varela-Rey MLuC, GarcíaTrevijano ER, Mato JM, Avila MA (2003) L-Methionine availability 
regulates expression of the methionine adenosyltransferase $2 \mathrm{~A}$ gene in human hepatocarcinoma cells. J Biol Chem 278:19885-19890

15. Tallan HH, Moore S, Stein WH (1958) L-Cystathionine in human brain. J Biol Chem 230:707-716

16. Okumura N, Kawai K (1961) Nitrogen metabolism of the brain. Folia Psychiatr Neurol Jpn 15:133-146

17. Dringer R (2000) Metabolism and function of glutathione in brain. Prog Neurol 62:649-671

18. Vitvitsky V, Thomas M, Ghorpade A, Gendelman HE, Banerjee $\mathrm{R}$ (2006) A functional trassulfuration pathaway in the brain links to glutathione homeostasis. J Biol Chem 281:35785-35793

19. Nussler AK, Billiar TR, Liu Z-Z, Morris MJ (1994) Coinduction of nitric oxide synthase and argininosuccinate synthetase in a murine macrophage cell line. J Biol Chem 269:1257-1261

20. Aksenov M, Aksenova M, Butterfield DA, Markesbery WR (2000) Oxidative modification of creatine kinase bb in Alzheimer's disease brain. J Neurochem 74:2520-2527

21. Bowen DM, Smith CD, White P, Dawson AN (1976) Neurotransmitter related enzymes and indices of hypoxia in senile dementia and other abiotrophies. Brain 99:459-496

22. Ramonet D, Rodriguez MJ, Fredriksson K, Bernal F, Mahy N (2004) In vivo neuroprotective adaptation of the Glutamate/ Glutamine cycle to neuronal death. Hippocampus 14:586-594

23. Chen J, Herrup K (2012) Glutamine act as a neuroprotectant against DNA damage, be-amyloid and $\mathrm{H}_{2} \mathrm{O}_{2}$-induced stress. PLoS One 7(3):e33177

24. Hamberger A, Jacobson I, Lindroth P, Mopper K, Nystrom B, Sandberg M, Molin S-O, Svanberg U (1981) Neuron-glia interactions in the biosynthesis and release of transmitter amino acids: in amino acid neurotransmitters. In: De Feudis FV, Mandel (eds) Raven Press, New York, pp 509-518

25. Procter AW, Palmer AM, Francis PT, Lowe SL, Neary D, Murphy E, Doshi R, Bowen DM (1988) Evidence of glutamatergic denervation and possible abnormal metabolism in Alzheimer's disease. J Neurochem 50:790-802

26. Fayed N, Modrego PJ, Rojas-Salinas G, Aguilar K (2011) Brain glutamate levels are decreased in Alzheimer's disease: a magnetic resonance spectroscopy study. Am J Alzheimers Dis Other Dem 26(6):450-456

27. Lee J, Ryu H, Ferrante RJ, Morris SM, Ratan RR (2002) Translational control of inducible nitric oxide synthase expression by arginine can explain the arginine paradox. PNAS 100(8):4843-4848

28. Auvinem M, Paasinem A, Andersson LC, Holta E (1992) Ornithine decarboxylase activity is critical for cell transformation. Nature 360:355-358

29. Raina AK, Monteiro MJ, Mc Shea A, Smith MA (1999) The role of cell cycle mediated events in Alzheimer's disease. Int Exp Path 80:71-76

30. LeBlanc A, Li H, Goodyer C, Bergeron C, Hammond J (1999) Caspase- 6 role in apoptosis of human neurons, amyloidogenesis, and Alzheimer's disease. J Biol Chem 274:23426-23436

31. Gervais FG, Xu D, Robertson GS, Vaillancourt JP, Zhu Y, Huang J, LeBlanc A, Smith D, Rigby M, Shearman MS, Clarke EE, Zheng H, Van Der Ploeg LHT, Ruffolo SC, Thornberry NA, Xanthoudakis S, Zamboni RJ, Roy S, Nicholson DW (1999) Involvement of caspases in proteolytic cleavage of Alzheimer's amyloid- $\beta$ precursor protein and amyloidogenic $A \beta$ peptide formation. Cell 97(3):395-406

32. Fafournoux P, Bruhat A, Jousse C (2000) Amino acid regulation of gene expression. Biochem J 351:1-12

33. Jousse C, Averous J, Bruhat A, Carraro V, Mordier S, Fafournoux $\mathrm{P}$ (2004) Amino acids as regulators of gene expression: molecular mechanisms. BBRC 313:447-452

34. Bruhat A, Jousse C, Carraro V, Reimold AM, Ferrara M, Fafournoux P (2000) Amino acids control mammalian gene trascription: activating transcription factor 2 is essential for the amino acid responsiveness of the CHOP promoter. Mol Cell Biol 20:7192-7204

35. Chen H, Pan Y-X, Dudenhausen EE, Kilberg MS (2004) Amino acid deprivation induces the trascription rate of the human asparagine synthetase gene through a timed program of expression and promoter binding of nutrient-responsive basic region/ leucine zipper transcription factors as well as localised histone acetylation. J Biol Chem 279:50829-50839

36. Shaheen HH, Horetsky RL, Kimball SR, Murthi A, Jefferson LS, Hopper AK (2007) Retrograde nuclear accumulation of cytoplasmic tRNA in rat hepatoma cells in response to amino acid deprivation. PNAS 104:8845-8850

37. Van Eldik LJ (2001) Glia and Alzheimer's disease. Neurochem Int 39:329-331 